\title{
Effect of Different Doses of Exercise on Sleep Duration, Sleep Efficiency and Sleep Quality in Sedentary, Overweight Men
}

Jonas S. Kjeldsen ${ }^{1,2}$, Mads Rosenkilde ${ }^{2}$, Signe W. Nielsen ${ }^{1}$, Michala Reichkendler ${ }^{2}$, Pernille Auerbach ${ }^{2}$, Thorkil Ploug $^{2}$, Bente Stallknecht ${ }^{2}$ Anders M. Sjödin ${ }^{1}$ and Jean-Philippe Chaput ${ }^{3 *}$

${ }^{1}$ Department of Nutrition, Exercise and Sports, Faculty of Science,University of Copenhagen, Copenhagen, Denmark.

${ }^{2}$ Department of Biomedical Sciences, Faculty of Health and Medical Sciences, University of Copenhagen, Copenhagen, Denmark.

${ }^{3}$ Healthy Active Living and Obesity Research Group,Children's Hospital of Eastern Ontario Research Institute, Ottawa, Canada.

\begin{abstract}
Objective: To evaluate the dose-response effect of aerobic exercise on sleep duration, sleep efficiency and sleep quality in previously sedentary, moderately overweight men.

Methods: In a randomized, controlled trial, 53 sedentary Caucasian men aged between 20 and 40 years $\left(\mathrm{VO}_{2^{-}}\right.$ max< $<5 \mathrm{~mL} \mathrm{O} \mathrm{kg}^{-1} \mathrm{~min}^{-1}$, BMl: $25-30 \mathrm{~kg} / \mathrm{m}^{2}$, body fat $>25 \%$ ) completed a 13-week aerobic exercise intervention consisting of either a physical activity energy deficit of $600 \mathrm{kcal}^{-1} \mathrm{y}^{-1}(\mathrm{HIGH}: \mathrm{n}=18), 300 \mathrm{kcal} \mathrm{day}^{-1}$ (MOD: $\left.n=18\right)$, or being sedentary (CON: $n=17)$. The endpoints were sleep duration (objectively measured by actigraphy over 3 days), sleep efficiency (3-day actigraphy), and subjectively rated sleep quality (Pittsburgh Sleep Quality Index).

Results: Because of missing sleep data, a total of 32 subjects were included in the present analysis (CON: $\mathrm{n}=12$, MOD: $\mathrm{n}=12, \mathrm{HIGH}: \mathrm{n}=8)$. A significant increase in sleep duration was observed in $\mathrm{HIGH}(80 \pm 30$ min, $p=0.03)$. However, the change was not significantly different from the change in CON. Sleep efficiency tended to decrease in HIGH ( $p=0.05)$, and there was a tendency towards an improved sleep quality within MOD and HIGH ( $p=0.08$ in both).

Conclusion: Our study suggests that a high daily dose of aerobic exercise for 13 weeks increases sleep duration, tends to decrease sleep efficiency, and tends to improve subjective sleep quality in sedentary, moderately overweight men. Because our sample included relatively young and sleep-efficient individuals, future studies should examine the dose-response effects of aerobic exercise on sleep parameters in older adults with sleeping problems.
\end{abstract}

Keywords: Sleep; Exercise; Physical activity; Adults; Overweight; RCT

\section{Introduction}

It is estimated that 50 to 70 million Americans chronically suffer from a disorder of sleep and wakefulness, hindering daily functioning and adversely affecting health and longevity [1]. The cumulative long-term effects of sleep deprivation and sleep disorders have been associated with a wide range of deleterious health consequences including an increased risk of depression, anxiety, obesity, diabetes, hypertension, heart attack, and stroke $[1,2]$. Sleep loss is an underrecognized public health problem that has cumulative effect on physical and mental health [3].

The high prevalence of sleep-related complaints and the limited efficacy of pharmacological treatments make nonpharmacological alternatives essential. Nonpharmacological approaches have slower but more durable effects than pharmacological treatments, without the undesirable side effects [4]. Physical activity is one such alternative that is accessible, inexpensive and affects numerous health systems simultaneously. It is generally believed that regular exercise can enhance sleep; however, there is a paucity of randomized controlled trials that have examined the effects of exercise on sleep. Although limited, the current literature indicates that moderate amounts of exercise, which can be obtained through a variety of means such as brisk walking and resistance training, are sufficient to improve sleep quality [5]. Moreover, epidemiological data indicate that exercise is the most important behavioral factor promoting sleep onset and improving sleep quality [6]. However, whether a dose-response relationship exists between the amount of exercise and the improvements in sleep duration and quality is unknown.

The objective of this study was to examine the effect of different doses of aerobic exercise on various sleep parameters in young previously sedentary, overweight but otherwise healthy men during a 13-week exercise intervention. We hypothesized that daily aerobic exercise would increase sleep duration and improve sleep efficiency and quality dependent of the exercise dose.

\section{Subjects and Methods}

\section{Subjects}

Volunteers were recruited through advertising in newspapers and on the internet. Inclusion criteria were: male sex, Caucasian race, age 20-40 years, body mass index (BMI) $25-30 \mathrm{~kg} / \mathrm{m}^{2}$, percent body fat $>25 \%$, maximal oxygen uptake $\left(\mathrm{VO}_{2}-\max \right)<45 \mathrm{~mL} \mathrm{~min}^{-1} \mathrm{~kg}^{-1}$, sedentary and healthy according to interview, fasting blood glucose $<6.1 \mathrm{mmol} \mathrm{L}^{-1}$, blood pressure $<140 / 90 \mathrm{~mm} \mathrm{Hg}$, and no first-degree relatives with type 2 diabetes. A total of 61 subjects complied with the inclusion criteria and were randomized to one of the three intervention groups: sedentary control $(\mathrm{CON})(\mathrm{n}=18)$, moderate-dose exercise (MOD) $(\mathrm{n}=21)$ or high-

${ }^{*}$ Corresponding author: Jean-Philippe Chaput, Ph.D., Healthy Active Living and Obesity Research Group, Children's Hospital of Eastern Ontario Research Institute, 401 Smyth Road, Ottawa, Ontario, Canada, K1H 8L1, Tel: 1613737 7600 ext. 3683; Fax: +1 613738 4800; E-mail: jpchaput@cheo.on.ca

Received August 10, 2012; Accepted October 22, 2012; Published October 24 2012

Citation: Kjeldsen JS, Rosenkilde M, Nielsen SW, Reichkendler M, Auerbach P, et al. (2012) Effect of Different Doses of Exercise on Sleep Duration, Sleep Efficiency and Sleep Quality in Sedentary, Overweight Men. Bioenergetics 2: 108. doi:10.4172/2167-7662.1000108

Copyright: ( 2012 Chaput JP, et al. This is an open-access article distributed under the terms of the Creative Commons Attribution License, which permits unrestricted use, distribution, and reproduction in any medium, provided the original author and source are credited. 
dose exercise $(\mathrm{HIGH})(\mathrm{n}=22)$. All subjects were tested pre-intervention, then randomized, and finally re-tested at the end of the intervention. A more extensive description of the study is provided elsewhere [7]. Subjects gave their informed written consent to participate in the study. The data presented here are part of a larger study on metabolic and cultural health in moderately overweight men (Project Four-IN-onE [FINE]; http://fine.ku.dk) and was approved by the ethics committee of the Capital Region of Denmark (H-4-2009-089) and adhered to the Helsinki Declaration. The study was also registered at http://www. clinicaltrials.gov with the identifying code NCT01430143.

\section{Exercise protocol}

Subjects were randomly assigned to CON, MOD or HIGH. Subjects in CON were instructed to maintain their sedentary lifestyle. Subjects in MOD and HIGH were instructed to perform daily aerobic exercise (running, cycling, rowing etc.) equivalent to an energy expenditure of 300 or $600 \mathrm{kcal} \mathrm{day}^{-1}$, respectively, corresponding to approximately 30 or $60 \mathrm{~min} \mathrm{day}^{-1}$. All subjects were instructed not to impose any dietary restriction throughout the intervention, but to continue eating a selfselected ad libitum diet, unless otherwise stated [7]. Subjects in MOD and HIGH had free access to fitness centers. Missed sessions (unless due to injury or illness) were to be compensated for during the following sessions. Three times per week exercise intensity had to be $>70 \%$ of $\mathrm{VO}_{2}$ max based on the maximum heart rate (HR) reserve method [8]. Exercise intensity at the remaining sessions was self-selected. Exercise was individually prescribed based on body mass, resting and maximal $\mathrm{HR}$, and $\mathrm{VO}_{2}$ max. The individual exercise target $\mathrm{HR}$ and training time were recalculated depending on changes in $\mathrm{VO}_{2}$ max and body weight after 2, 6 and 10 weeks. Subjects in MOD and HIGH were contacted by phone by the researchers every second day during the first two weeks to ensure exercise compliance and for supervision and motivation, and were asked to visit the department once a week during the entire intervention to verify and control exercise sessions. Subjects wore HR monitors (RS400, Polar Electro OY, Kempele, Finland) during all exercise sessions that stored exercise $\mathrm{HR}$, number and duration of exercise sessions, and calculated training energy expenditure [9]. Subjects in CON were sparsely contacted to minimize any enrollment effect, and were offered consultations regarding "healthy" lifestyle changes after the intervention. Subjects were excluded if they deviated $>$ $20 \%$ from the prescribed exercise dose. Additionally, 2 of the following 3 criteria had to be met: (i) at least $80 \%$ of the intervention days should include exercise; (ii) $80 \%$ of exercise sessions should include registration of HR; (iii) less than $20 \%$ of days without training due to illness or injury.

\section{Pre- and post-intervention measurements}

Sleep assessment: Subjects were asked to wear an actigraph (ActiGraph GT1M, Pensacola, FL, USA) around the waist for three consecutive days and nights $(72 \mathrm{~h})$, and were only allowed to remove the device when bathing or swimming. The ActiGraph GT1M is an accelerometer designed to detect vertical accelerations in the range $0.05-2.0 \mathrm{~g}$ with a frequency response of $0.25-2.5 \mathrm{~Hz}$ and senses motion using integrated circuitry [10]. Accelerometry data were downloaded as 1-min epochs and subjects were included in the sleep analyses only if two out of three actigraph nights before as well as after the intervention were valid according to our criteria for sleep determination (see below). We used the ActiLife software (ActiLife 5.5.5, Pensacola, FL, USA) to determine sleep duration and sleep efficiency, based on the following criteria:

Sleep onset: The first period of 20 min duration with activity counts below 100. Total duration before wake up should be $>3$ hours with no period lasting $5 \mathrm{~min}$ or longer with activity counts above 100 .
Time for wake up: Activity counts above 100 for at least 5 min with no repeated sleep onset the subsequent $90 \mathrm{~min}$.

Sleep duration was defined as the period from sleep onset until wake up, excluding nocturnal awakenings, and was determined as the average of the three (or two) nights of sleep. Nocturnal awakenings comprised arousal periods with an activity count above 100 for 1 minute or longer. Furthermore, sleep efficiency was defined as the percentage of the period from sleep onset until wake up the subject was actually asleep (actual sleep duration divided by registered sleep duration). The Cole-Kripke algorithm was used to calculate sleep duration and sleep efficiency, since it is suitable for this specific age group [11].

Moreover, each participant completed the Pittsburgh Sleep Quality Index (PSQI), a self-rated questionnaire that assesses sleep quality over the preceding 1-month time interval [12]. Briefly, 19 individual items generate seven component scores: subjective sleep quality, sleep latency, sleep duration, habitual sleep efficiency, sleep disturbances, use of sleeping medication, and daytime dysfunction. The sum of the component scores yields one total score with a maximum of 21 . A total PSQI-score greater than 5 is highly sensitive and specific in distinguishing good from poor sleepers, and has been validated in a number of populations [13]. A high score indicates poor sleep quality.

\section{Body mass index}

Weight was measured on an electronic scale and height was measured using a stadiometer according to standardized procedures. Body mass index was calculated as body weight divided by height squared $\left(\mathrm{kg} / \mathrm{m}^{2}\right)$.

\section{Maximal aerobic capacity}

$\mathrm{VO}_{2}$ max was determined by a graded exercise test on a bicycle ergometer (Lode Excalibur, Groeningen, Netherlands). Workload was increased with $25 \mathrm{~W}$ increments every minute after warm-up until exhaustion and attainment of $\mathrm{VO}_{2}$ max was accepted. Pulmonary ventilation, uptake of oxygen and excretion of carbon dioxide were registered every $10 \mathrm{~s}$ by an online system (Oxycon Pro; Jaeger, Würzberg, Germany), and HR was monitered by telemetry (Polar Wear Link 31 transmitter; Polar Electro, Kempele, Finland). Subjects performed a familiarization $\mathrm{VO}_{2}$ peak-test prior to the $\mathrm{VO}_{2}$ max test. Criteria for reaching $\mathrm{VO}_{2}$ max were a leveling off in $\mathrm{O}_{2}$ consumption despite increases in workload and a respiratory exchange ratio $>1.15$ [14].

\section{Statistical analysis}

A paired $t$-test was performed to investigate the effects of the intervention within groups. To identify differences between the three groups a one-way analysis of variance (ANOVA) was performed, and the pair-wise comparisons were adjusted using the Holm-Sidak procedure. The non-parametric Kruskal-Wallis ANOVA on ranks was used to test for differences between the groups if the data did not follow normal distribution (comparison of baseline sleep duration and baseline sleep efficiency). An unpaired t-test was used to assess differences in baseline characteristics between the included and the excluded subjects. All results are presented as mean \pm SEM and the statistical analyses were conducted using Sigma Plot version 12.0 (Systat Software Inc., San Jose, CA, USA). A two-tailed $P$ value of less than 0.05 was considered to indicate statistical significance.

\section{Results}

Of the 61 subjects that were randomized, 53 subjects completed the intervention and conducted actigraph measurements. A total of 
Citation: Kjeldsen JS, Rosenkilde M, Nielsen SW, Reichkendler M, Auerbach P, et al. (2012) Effect of Different Doses of Exercise on Sleep Duration, Sleep Efficiency and Sleep Quality in Sedentary, Overweight Men. Bioenergetics 2: 108. doi:10.4172/2167-7662.1000108

Page 3 of 6

A

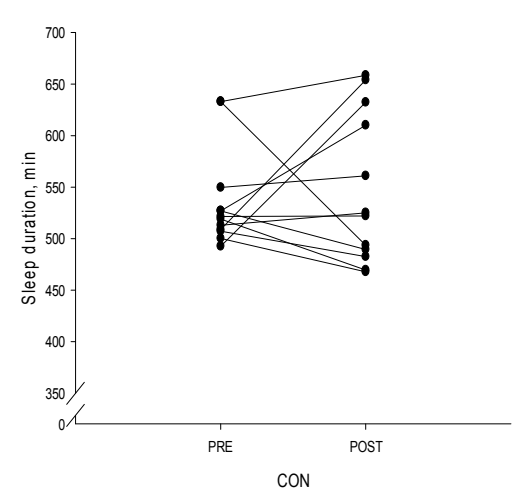

$\mathrm{CON}=$ control group. $\mathrm{n}=12$.

Figure 1a: Sleep duration at baseline and after the intervention for subjects in the control group.

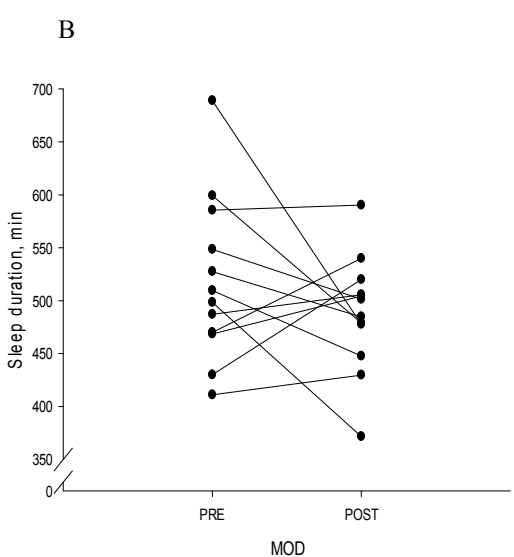

MOD=moderate-dose exercise group $\left(300 \mathrm{kcal} \mathrm{day}^{-1}\right) . \mathrm{n}=12$.

Figure 1b: Sleep duration at baseline and after the intervention for subjects in the moderate-dose exercise group.

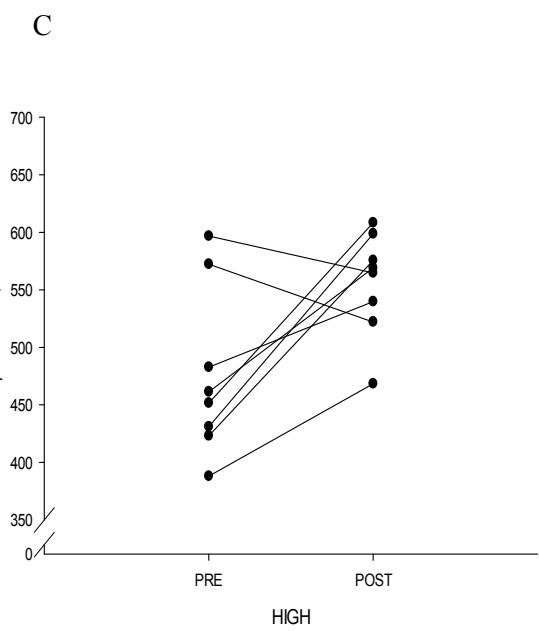

$\mathrm{HIGH}=$ high-dose exercise group $\left(600 \mathrm{kcal}^{\mathrm{day}}{ }^{-1}\right) . \mathrm{n}=8$.

Figure 1c: Sleep duration at baseline and after the intervention for subjects in the high-dose exercise group.
21 subjects were excluded from the sleep analysis due to the following reasons: 11 subjects due to missing pre- or post-measurements (10 pre, 1 post), 5 subjects due to missing actigraph data for 2 days/nights, and 5 subjects due to a lack of wake up recordings after 2 out of the 3 nights, according to our criteria. As shown in table 1, the final group of subjects included 32 overweight (BMI: $\left.28 \pm 0 \mathrm{~kg} / \mathrm{m}^{2}\right)$, sedentary $\left(\mathrm{VO}_{2} \max : 35.4 \pm\right.$ $0.8 \mathrm{~mL} \mathrm{O}_{2} \mathrm{~min}^{-1} \mathrm{~kg}^{-1}$ ) men in the age of $29 \pm 1$ years (CON: $\mathrm{n}=12$, MOD: $\mathrm{n}=12$, HIGH: $\mathrm{n}=8$ ). There were no statistically significant differences between participants retained and those excluded according to weight $(\mathrm{p}=0.15)$, absolute $\mathrm{VO}_{2} \max (\mathrm{p}=0.77)$ and relative $\mathrm{VO}_{2} \max (\mathrm{p}=0.66)$, suggesting that any selection bias is unlikely. During the intervention average adherence to the prescribed exercise was equally high in MOD and HIGH $(\mathrm{P}>0.1)$, and there was no difference in exercise intensity and number of exercise sessions conducted during the intervention between the exercise groups $(\mathrm{P}>0.1)$.

\section{$\mathrm{D}$}

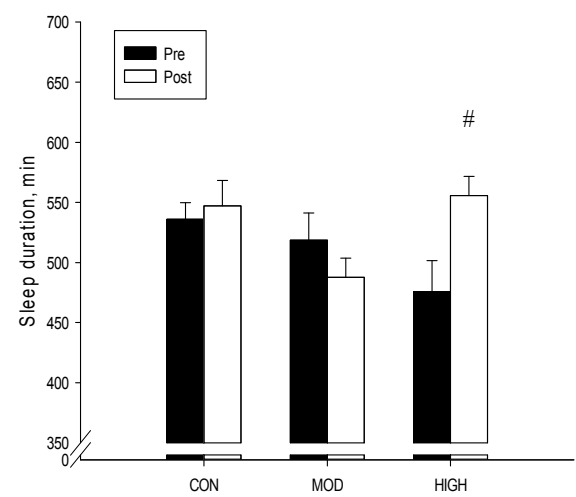

Results are presented as mean \pm SEM. \# indicates significant change within the group. $\mathrm{CON}=$ control group; $\mathrm{MOD}=$ moderate-dose exercise group (300 kcal day $\left.{ }^{-1}\right) ; \mathrm{HIGH}=$ high-dose exercise group (600 kcal day $\left.{ }^{-1}\right)$. CON: $n=12$, MOD: $n=12, \mathrm{HIGH}: n=8$. A paired t-test was performed to investigate changes within groups. A one-way analysis of variance (ANOVA) was performed to assess differences between groups, and the pair-wise comparisons were adjusted using the Holm-Sidak procedure. The non-parametric KruskalWallis ANOVA on ranks was used to test for differences in baseline sleep duration between the groups, since the data did not follow normal distribution. Figure 1d: Sleep duration at baseline and after the intervention for all three intervention groups.

\begin{tabular}{|c|c|c|c|c|c|c|}
\hline & \multicolumn{2}{|c|}{$\operatorname{CON}(n=12)$} & \multicolumn{2}{|c|}{$\operatorname{MOD}(n=12)$} & \multicolumn{2}{|l|}{$\mathrm{HIGH}(n=8)$} \\
\hline & Pre & Post & Pre & Post & Pre & Post \\
\hline Weight, kg & $92.9 \pm 2.5$ & $\begin{array}{l}92.7 \pm \\
2.6\end{array}$ & $\begin{array}{l}94.0 \pm \\
2.4\end{array}$ & $\begin{array}{l}90.9 \pm \\
2.5^{* \#}\end{array}$ & $94.5 \pm 2.6$ & $90.8 \pm 2.2^{* \#}$ \\
\hline $\begin{array}{l}\text { Body mass } \\
\text { index }(\mathrm{kg} / \\
\left.\mathrm{m}^{2}\right)\end{array}$ & $28 \pm 1$ & $28 \pm 1$ & $29 \pm 0$ & $28 \pm 1^{* \#}$ & $28 \pm 0$ & $27 \pm 0$ \#\# \\
\hline $\begin{array}{l}\mathrm{VO}_{2} \max , \mathrm{L} \\
\mathrm{O}_{2} \mathrm{~min}^{-1}\end{array}$ & $3.3 \pm 0.1$ & $3.4 \pm 0.1$ & $3.3 \pm 0.1$ & $3.8 \pm 0.1^{* \#}$ & $3.2 \pm 0.1$ & $3.7 \pm 0.1^{\text {*\# }}$ \\
\hline $\begin{array}{l}\mathrm{VO}_{2} \max , \mathrm{mL} \\
\mathrm{O}_{2} \mathrm{~min}^{-1} \mathrm{~kg}^{-1}\end{array}$ & $35.9 \pm 1.6$ & $\begin{array}{l}36.8 \pm \\
1.1\end{array}$ & $\begin{array}{l}36.1 \pm \\
1.3\end{array}$ & $\begin{array}{l}43.1 \pm \\
1.6^{* \#}\end{array}$ & $33.7 \pm 1.1$ & $41.1 \pm 1.5^{\text {*\# }}$ \\
\hline
\end{tabular}

*Indicates significant change compared to the change in CON.

\# Indicates significant change within the group.

$\mathrm{CON}=$ control group.

MOD $=$ moderate-dose exercise group $\left(300 \mathrm{kcal} \mathrm{day}^{-1}\right)$.

$\mathrm{HIGH}=$ high-dose exercise group $\left(600 \mathrm{kcal} \mathrm{day}^{-1}\right)$.

A one-way analysis of variance (ANOVA) was performed to assess differences between groups, and the pair-wise comparisons were adjusted using the HolmSidak procedure. A paired t-test was performed to assess changes within groups.

Table 1: Participant characteristics at baseline and after the intervention. 
Citation: Kjeldsen JS, Rosenkilde M, Nielsen SW, Reichkendler M, Auerbach P, et al. (2012) Effect of Different Doses of Exercise on Sleep Duration, Sleep Efficiency and Sleep Quality in Sedentary, Overweight Men. Bioenergetics 2: 108. doi:10.4172/2167-7662.1000108

Sleep duration at baseline and after the intervention is presented in (Figures 1A-D). Sleep duration, sleep efficiency and sleep quality were not significantly different between any of the three groups at baseline ( $p>0.08$ ). We observed that 6 out of 8 subjects in HIGH increased their sleep duration (Figure 1C), resulting in a $17 \%$ increase in sleep duration within HIGH (pre: $476 \pm 26 \mathrm{~min}$, post: $556 \pm 16 \mathrm{~min}, p=0.03$ ) (Figure 1D). Sleep duration did not change within CON (pre: $536 \pm 14 \mathrm{~min}$, post: $547 \pm 21 \mathrm{~min}, p=0.64$ ) and MOD (pre: $519 \pm 22 \mathrm{~min}$, post: $488 \pm$ $16 \mathrm{~min}, \mathrm{p}=0.25$ ). The change in sleep duration within HIGH was not statistically different from the change within CON $(\Delta$ sleep duration HIGH: $80 \pm 30 \mathrm{~min}$ and $\Delta$ sleep duration CON: $11.1 \pm 23 \mathrm{~min}, p=0.16$ ), but greater compared to the change within $\operatorname{MOD}(\Delta$ sleep duration HIGH: $80 \pm 30 \mathrm{~min}$ and $\Delta$ sleep duration MOD: $-31 \pm 26 \mathrm{~min}, p=0.02$ ) (Figure 1D)

Sleep efficiency was nearly $100 \%$ in all three groups before the intervention, and tended to decrease during the intervention within HIGH (pre: $97.5 \pm 0.2 \%$, post: $95.7 \pm 0.7 \%, p=0.05$ ), but not within CON (pre: $97.3 \pm 0.4 \%$, post: $97.0 \pm 0.4 \%, p=0.52$ ) and MOD (pre: 96.9 $\pm 0.7 \%$, post: $96.1 \pm 0.7 \%, p=0.31$ ).

\section{A}

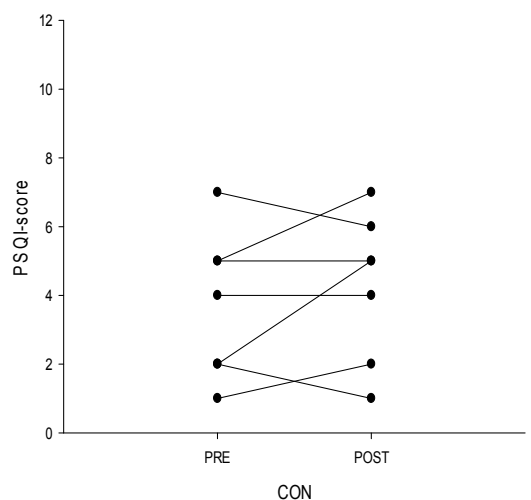

PSQI = Pittsburgh Sleep Quality Index. CON=Control Group. n=12.

Figure 2a: Sleep quality at baseline and after the intervention for subjects in the control group.

B

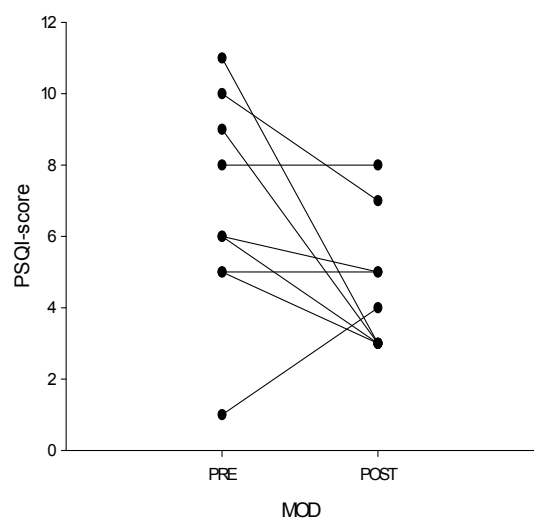

PSQI=Pittsburgh Sleep Quality Index. MOD=Moderate-dose Exercise Group $\left(300\right.$ kcal day $\left.^{-1}\right) \cdot n=12$.

Figure 2b: Sleep quality at baseline and after the intervention for subjects in the moderate-dose exercise group.

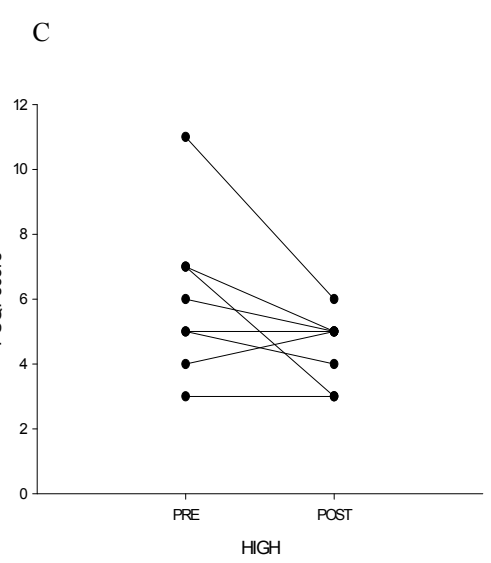

PSQI=Pittsburgh Sleep Quality Index. HIGH=High-dose Exercise Group (600 kcal day-1). $n=8$.

Figure 2c: Sleep quality at baseline and after the intervention for subjects in the high-dose exercise group.

\section{$\mathrm{D}$}

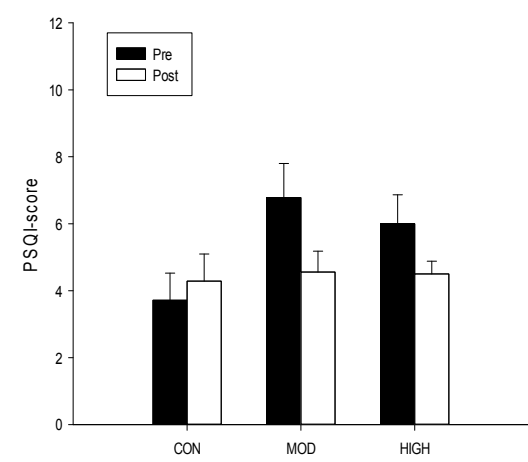

PSQI=Pittsburgh Sleep Quality Index. CON=control group, MOD=Moderatedose Exercise Group (300 kcal day ${ }^{-1}$ ), HIGH=High-dose Exercise Group (600 kcal day $\left.{ }^{-1}\right)$. CON: $n=12$, MOD: $n=12, H I G H: n=8$. A paired t-test was performed to assess changes within groups. A one-way analysis of variance (ANOVA) was performed to assess differences between groups, and the pairwise comparisons were adjusted using the Holm-Sidak procedure.

Figure 2d: Sleep quality at baseline and after the intervention for all three intervention groups.

Sleep quality at baseline and after the intervention is presented in (Figures 2A-D). There was a tendency towards an improved sleep quality measured by the PSQI-questionnaire within MOD (pre: $6.8 \pm$ 1.0 , post: $4.6 \pm 0.6, p=0.08$ ) and HIGH (pre: $6.0 \pm 0.9$, post: $4.5 \pm 0.4$, $p=0.08$ ), which was not observed within CON (pre: $3.7 \pm 0.8$, post: $4.3 \pm$ $0.8, \mathrm{p}=0.36$ ) (Figure 2D). According to the classification of sleep quality, the PSQI-scores indicated that 6 out of 9 subjects in MOD (Figure 2B), and 4 out of 8 the subjects in HIGH were poor sleepers before the intervention (Figure 2C). Improvements in sleep quality were observed in 6 out of 9 subjects in MOD, and 5 out of 8 in HIGH, with only 2 subjects in MOD and 1 subject in HIGH having PSQI-scores above 5, indicating sleep problems in these subjects (Figure 2B and 2C).

\section{Discussion}

Collectively, we observed that a high daily dose of aerobic exercise for 13 weeks resulted in a significant increase in sleep duration in 
previously sedentary, moderately overweight, but otherwise healthy men. However, the change in sleep duration was not significantly different from the change within the sedentary control group. The majority of the subjects decreased their PSQI-score following a moderate or a high daily dose of aerobic exercise for 13 weeks, indicating that aerobic exercise affects subjectively-rated sleep quality in a positive way.

To our knowledge, Shapiro et al. [15] were the first to investigate the longitudinal effects of aerobic exercise on sleep pattern [15]. They observed that 18 weeks of exercise led to a significant increased proportion of slow wave sleep (SWS), which is thought to be the deepest and most restorative part of sleep, and a large proportion of SWS indicates good sleep quality $[15,16]$. The effect of exercise on sleep architecture has later been investigated in other studies in both patients and non-patient populations [17-19]. As far as we know, our study is the first randomized controlled trial investigating the dose-response effects of daily aerobic exercise on sleep pattern in sedentary, moderately overweight, but otherwise healthy men, measured under free-living conditions. The increase in sleep duration observed after a high daily dose of aerobic exercise is in agreement with the findings of others, conducted in different populations with different methodological approaches [20,21], and is supported by findings in animal studies $[22,23]$. The increase in sleep duration is thought to be attributable to feelings of fatigue, which may be perceived as tiredness by these subjects. These subjects went from being sedentary and not engaged in any regular exercise to exercising approximately one hour every day. This drastic change in their physical activity level may conceivably have caused a greater need for relaxation and rest. Some traditional theories have been proposed to explain the sleep-promoting effects of exercise, and they include the thermoregulatory, the body restoration and the energy conservation hypotheses $[5,16,24]$. Longer sleep duration after a high daily dose of exercise should thus be seen as a normal physiological adaptation that allows the body to recover from the workload imposed by exercise.

Our results also suggest an effect of aerobic exercise on sleep quality, which is in accordance with the findings observed in several other longitudinal studies, generally reporting improved sleep quality following exercise programs $[18,20,21,25,26]$. However, differences in study populations in the different studies limit the ability to compare our results with the results from other studies. Inclusion of women, older adults and patients with sleep complaints or insomnia in other studies might have caused different effects of the exercise interventions. Besides differences in study populations, the combination of exercise and sleep hygiene education in some studies limits the ability to evaluate the relative effects of the different treatments on sleep quality $[20,26]$. Sleep complaints, sleep fragmentation, short sleep durations and symptoms of insomnia are common phenomena in the elderly and in postmenopausal women $[21,27,28]$. It is therefore expected that more pronounced effects of exercise on sleep could be observed in older adults and in people with sleep complaints, due to a greater "room for improvement" in these individuals.

The effect of exercise on sleep duration and quality observed in the present study can possibly be attributed to improvements in other parameters than fitness. Improvements in mood and feelings of higher mental and physical energy levels following exercise could conceivably have caused shorter sleep onset latency and less sleep fragmentations, resulting in better and longer sleep. This corresponds well with studies showing that exercise is associated with reductions in anxiety symptoms and decreased levels of depression and stress, which both are thought to be important factors regarding the onset and maintenance of sleep [5,29-31].
Our study population includes relatively young and fairly good sleepers, with a relatively limited room for improvement with regard to sleep efficiency. Sleep efficiency was almost $100 \%$ in all three groups before and after the intervention, and thereby suggests a ceiling effect in this sleep parameter. Although sleep efficiency tended to decrease within HIGH (from 97.5 to $95.7 \%, p=0.05$ ), the value is still very high and does not suggest that sleep efficiency is poor for individuals engaging in high daily doses of aerobic exercise. Future studies should examine the dose-response effect of exercise on sleep efficiency in "atrisk" individuals (e.g. older adults having sleep problems).

There are several limitations associated with the present study. It is generally believed that accelerometry is a valid and reliable tool for sleep assessment in healthy adult populations, but the validity is questioned when sleep becomes more fragmented [32]. Actigraphs are usually worn around the wrist to assess sleep, and around the waist/ trunk to assess physical activity [10,33,34], and the validation of the present sleep-scoring algorithm was conducted based on wrist-worn actigraphs [11]. However, good agreements between sleep/wake identifications and estimations of total sleep duration by wrist and waist actigraphy are reported [10,35-37]. Due to the lack of sleep diaries, we had to rely solely on the researchers' identification of sleep based on the selected criteria, which probably has caused misscoring of sleep in some cases. However, good agreements between sleep durations calculated based on researcher-estimates of bedtime and time for wake up from actigraphy, and sleep durations based on sleep diaries have recently been reported [10]. Subjects in HIGH could possibly be thought to rest for a longer period close to bedtime due to stronger feelings of fatigue, which potentially caused a more pronounced misscoring of sleep in this group. It is generally recommended that sleep monitoring should be conducted for at least three consecutive days and nights [38-40], and the fact that actigraph data from some subjects were based on only two nights might have increased the variability of our data.

Reliance on self-reported measures of sleep quality may conceivably have been associated with recall bias. Furthermore, the sleep study was designed ad hoc, after the overall study design was made, and sleep parameters were therefore not included a priori in the study design. Power calculations were thus not conducted based on sleep data, and the relatively small sample size might disguise appearance of true differences between groups or within groups, thereby increasing the risk of type 2 errors. We were also not able to detect potential changes in sleep architecture following the exercise intervention, due to the fact that the actigraph does not provide information about time spent in different sleep stages. Finally, the external generalizability of our findings may be restricted to Caucasian, sedentary, moderately overweight men.

In summary, the present study suggests that a high daily dose of aerobic exercise for 13 weeks increases sleep duration, tends to decrease sleep efficiency, and tends to improve subjective sleep quality in sedentary, moderately overweight men. Future work should determine the dose-response effects of aerobic exercise on sleep parameters in older adults having sleep problems in order to avoid the ceiling effect observed with sleep efficiency.

\section{Acknowledgements}

This work was carried out as part of the UNIK research program (Food, Fitness \& Pharma for Health and Disease, http://foodfitnesspharma.ku.dk). The UNIK project is supported by the Danish Ministry of Science, Technology and Innovation. Further financial support was obtained from the Novo Nordisk Foundation. Collaborators, students and technical staff that made this intervention work included Astrid Pernille Jespersen, Julie Bønnelycke, Thomas Christian Bonne, Line Quist Bendsen, Charlotte Stephansen, Marie-Louise Udengaard, Martin Bæk Pedersen, Finna Sigurdardottir, Helle Roager Jensen, Mia Lundby Kragelund, 
Citation: Kjeldsen JS, Rosenkilde M, Nielsen SW, Reichkendler M, Auerbach P, et al. (2012) Effect of Different Doses of Exercise on Sleep Duration, Sleep Efficiency and Sleep Quality in Sedentary, Overweight Men. Bioenergetics 2: 108. doi:10.4172/2167-7662.1000108

Anne Sofie Gram, Anders Lagerberg, Jannie Østergaard, Hanne Thorvig, Julie Sams Agerschou, Smita Kunwar, Thomas Beck, Gerda Hau and Jakob Utzon Franck. Jean-Philippe Chaput holds a Junior Research Chair in Healthy Active Living and Obesity Research.

\section{References}

1. Institute of Medicine (US) (2006) Committee on Sleep Medicine and Research

2. Chaput JP, Tremblay A (2012) Insufficient sleep as a contributor to weight gain: an update. Curr Obes Rep 1: 245-256.

3. Chaput JP (2010) A good night's sleep for a healthier population. Am J Prev Med 38: 349.

4. Morin CM, Hauri PJ, Espie CA, Spielman AJ, Buysse DJ, et al. (1999) Nonpharmacologic treatment of chronic insomnia. An American Academy of Sleep Medicine review. Sleep 22: 1134-1156.

5. Buman MP, King AC (2010) Exercise as a treatment to enhance sleep. Am J Lifestyle Med 4: 500-514.

6. Urponen H, Vuori I, Hasan J, Partinen M (1988) Self-evaluations of factors promoting and disturbing sleep: an epidemiological survey in Finland. Soc Sci Med 26: 443-450.

7. Rosenkilde M, Auerbach P, Reichkendler MH, Ploug T, Stallknecht BM, et al. (2012) Body fat loss and compensatory mechanisms in response to different doses of aerobic exercise-a randomized controlled trial in overweight sedentary males. Am J Physiol Regul Integr Comp Physiol 303: R571-579.

8. Karvonen MJ, Kentala E, Mustala O (1957) The effects of training on heart rate: a longitudinal study. Ann Med Exp Biol Fenn 35: 307-315.

9. Crouter SE, Albright C, Bassett DR Jr. (2004) Accuracy of polar S410 heart rate monitor to estimate energy cost of exercise. Med Sci Sports Exerc 36: 1433-1439.

10. Kinder JR, Lee KA, Thompson H, Hicks K, Topp K, et al. (2012) Validation of a hip-worn accelerometer in measuring sleep time in children. $\mathrm{J}$ Pediatr Nurs 27: $127-133$.

11. Cole RJ, Kripke DF, Gruen W, Mullaney DJ, Gillin JC (1992) Automatic sleep/ wake identification from wrist activity. Sleep 15: 461-469.

12. Buysse DJ, Reynolds CF 3rd, Monk TH, Berman SR, Kupfer DJ (1989) The Pittsburgh sleep quality index: a new instrument for psychiatric practice and research. Psychiatry Res 28: 193-213.

13. Carpenter JS, Andrykowski MA (1998) Psychometric evaluation of the Pittsburgh sleep quality index. J Psychosom Res 45: 5-13.

14. Duncan GE, Howley ET, Johnson BN (1997) Applicability of $\mathrm{VO}^{2}$ max criteria: discontinuous versus continuous protocols. Med Sci Sports Exerc 29: 273-278.

15. Shapiro CM, Warren PM, Trinder J, Paxton SJ, Oswald I, et al. (1984) Fitness facilitates sleep. Eur J Appl Physiol Occup Physiol 53: 1-4.

16. Youngstedt SD (2005) Effects of exercise on sleep. Clin Sports Med 24: 355 365.

17. Driver HS, Meintjes AF, Rogers GG, Shapiro CM (1988) Submaximal exercise effects on sleep patterns in young women before and after an aerobic training programme. Acta Physiol Scan Suppl 574: 8-13.

18. King AC, Pruitt LA, Woo S, Castro CM, Ahn DK, et al. (2008) Effects of moderate-intensity exercise on polysomnographic and subjective sleep quality in older adults with mild to moderate sleep complaints. J Gerontol A Biol Sci Med Sci 63: 997-1004.

19. Kline CE, Crowley EP, Ewing GB, Burch JB, Blair SN, et al. (2011) The effect of exercise training on obstructive sleep apnea and sleep quality: a randomized controlled trial. Sleep 34: 1631-1640.

20. Reid KJ, Baron KG, Lu B, Naylor E, Wolfe L, et al. (2010) Aerobic exercise improves self-reported sleep and quality of life in older adults with insomnia. Sleep Med 11: 934-940.

21. King AC, Oman RF, Brassington GS, Bliwise DL, Haskell WL (1997) Moderateintensity exercise and self-rated quality of sleep in older adults. A randomized controlled trial. JAMA 277: 32-37.

22. Gambelunghe C, Mariucci G, Rossi R, Sommavilla M, Tantucci M, et al. (2005) Effects of light physical exercise on sleep in middle-aged rats. Int J Sports Med 26: 327-331.
23. Gambelunghe C, Rossi R, Mariucci G, Tantucci M, Ambrosini MV (2001) Effects of light physical exercise on sleep regulation in rats. Med Sci Sports Exerc 33 $57-60$

24. Driver HS, Taylor SR (2000) Exercise and sleep. Sleep Med Rev 4: 387-402.

25. Mansikkamäki K, Raitanen J, Nygård CH, Heinonen R, Mikkola T, et al. (2012) Sleep quality and aerobic training among monopausal women - A randomized controlled trial. Mauritas 72: 339-345

26. Gebhart G, Erlacher D, Schredl M (2011) Moderate exercise plus sleep education improves self-reported sleep quality, daytime mood, and vitality in adults with chronic sleep complaints: a waiting list-controlled trial. Sleep Disorders 2011: 1-10.

27. Foley DJ, Monjan AA, Brown SL, Simonsick EM, Wallace RB, et al. (1995) Sleep complaints among elderly persons: an epidemiologic study of three communities. Sleep 18: 425-432.

28. Moilanen J, Aalto AM, Hemminki E, Aro AR, Raitanen J, et al. (2010) Prevalence of monopause symptoms and their association with lifestyle among Finish middle-aged women. Mauritas 67: 368-374.

29. Herring MP, O'Connor PJ, Dishman RK (2010) The effect of exercise training on anxiety symptoms among patients: a systematic review. Arch Intern Med 170: $321-331$.

30. Dunn AL, Trivedi MH, Kampert JB, Clark CG, Chambliss HO (2005) Exercise treatment for depression: efficacy and dose response. Am J Prev Med 28: 1-8.

31. Gerber M, Brand S, Holsboer-Trachsler E, Puhse U (2010) Fitness and exercise as correlates of sleep complaints: is it all in our minds? Med Sci Sports Exerc 42: 893-901.

32. Ancoli-Israel S, Cole R, Alessi C, Chambers M, Moorcroft W, et al. (2003) The role of actigraphy in the study of sleep and circadian rhythms. Sleep 26: 342 392

33. Enomoto M, Endo T, Suenaga K, Miura N, Nakano Y, et al. (2009) Newly developed waist actigraphy and its sleep/wake scoring algorithm. Sleep Bio Rhythms 7: 17-22.

34. Meijer GA, Westerterp KR, Verhoeven FM, Koper HB, ten Hoor F (1991) Methods to assess physical activity with special reference to motion sensors and accelerometers. IEEE Trans Biomed Eng 38: 221-229.

35. Middelkoop HA, van Dam EM, Smilde-van den Doel DA, Van Dijk G (1997) 45-hour continuous quintuble-site actimetry: relations between trunk and limb movements and effects of circadian sleep-wake rhythmicity. Psychophysiology 34: 199-203.

36. Paavonen EJ, Fjällberg M, Steenari MR, Aronen ET (2002) Actigraph placement and sleep estimation in children. Sleep 25: 235-237.

37. Hjorth MF, Chaput JP, Damsgaard CT, Dalskov S, Michaelsen KF, et al. (2012) Measure of sleep and physical activity by a single accelerometer: can a waistworn actigraph adequately measure sleep in children? Sleep Biol Rhythms 10 328-335.

38. Littner M, Kushida CA, Anderson WM, Bailey D, Berry RB, et al. (2003) Practice parameters for the role of actigraphy in the study of sleep and circadian rhythms: an update for 2002. Sleep 26: 337-341

39. Sadeh A, Hauri PJ, Kripke DF, Lavie P (1995) The role of actigraphy in the evaluation of sleep disorders. Sleep 18: 288-302.

40. Sadeh A (2011) The role and validity of actigraphy in sleep medicine: an update Sleep Med Rev 15: 259-267. 